\title{
Macrofungal diversity in Colombian Amazon forests varies with regions and regimes of disturbance
}

\author{
Carlos A. López-Quintero • Gerben Straatsma • \\ A. Esperanza Franco-Molano • Teun Boekhout
}

Received: 8 April 2011/ Accepted: 23 March 2012/Published online: 13 April 2012

(C) The Author(s) 2012. This article is published with open access at Springerlink.com

\begin{abstract}
Here we present the results of fungal biodiversity studies from some selected Colombian Amazon forests in relationship to plant biodiversity and successional stages after slash and burn agriculture. Macrofungal diversity was found to differ between forests occurring in two regions (Araracuara vs Amacayacu) as well as between flooded forests and terra firme forests in the Amacayacu region. Macrofungal biodiversity differed between regeneration states of different age in the Araracuara region. Suitable substrates, especially dead wood that occurred as a result of recent slash and burn agriculture, resulted in the formation of many sporocarps of wood-inhabiting species. Putative ectomycorrhizal species were found in a dipterocarp forest. Fifty two percent of the macrofungal species could not be identified to the species level, but could be assigned to a genus, and it is likely that a significant portion of these represent species new to science. Long term studies are needed to obtain a comprehensive and complete understanding of the diversity and functioning of mycobiota in Amazon forest ecosystems.
\end{abstract}

Keywords Amazon forest $\cdot$ Biodiversity $\cdot$ Colombia $\cdot$ Ecology $\cdot$ Macrofungi · Plants · Productivity

Electronic supplementary material The online version of this article (doi:10.1007/s10531-012-0280-8) contains supplementary material, which is available to authorized users.

C. A. López-Quintero · A. E. Franco-Molano

Laboratorio TEHO, Instituto de Biología, Universidad de Antioquia, P.O. Box 1226,

Calle 67 \# 53-108, Medellín, Colombia

G. Straatsma

Aquatic Ecology and Water Quality Management Group, Wageningen University \& Research Center, P.O. Box 47, 6700 AA, Wageningen, The Netherlands

T. Boekhout $(\bowtie)$

CBS-KNAW Fungal Biodiversity Centre, P.O. Box 85167, 3508 AD Utrecht, The Netherlands

e-mail: t.boekhout@cbs.knaw.nl 


\section{Introduction}

Fungi are an essential functional component of terrestrial ecosystems as decomposers, symbionts and pathogens (Mueller et al. 2007) and they represent one of the most biodiverse groups of organisms on earth (Hawksworth 1991, 2001). However, our knowledge of their diversity and ecological function in Neotropical lowland forests is limited. The ecological interaction of macrofungi with other organisms in these forests is poorly understood due to the largely unexplored, but likely huge, fungal diversity, as well as the cryptic and ephemeral nature of many fungal species. Incomplete information on the biodiversity of macrofungi from such ecosystems is only available from scattered sources (Lodge and Cantrell 1995; Lodge 1997; Jiménez-Valverde and Hortal 2003; Piepenbring 2007; Schmit and Mueller 2007; Swapna et al. 2008). A major part of the global but unknown fungal biodiversity is assumed to occur in tropical regions, where the diversity of fungi may be higher than in temperate regions, because of more favorable environmental conditions throughout the year, a higher diversity of vascular plants that create niches and microhabitats for fungi, and the presence of many ecotones (Hawksworth 2001; Kark 2007). The diversity of macrofungi in tropical forests as assessed by Lodge et al. (1995) showed that the highest diversity in the Neotropics occurred in the Amazon basin with aphyllophoralean, pyrenomycetous, xylariaceous and hyphomycetous fungi being most species rich.

The Amazonian rainforest is arguably the most species-rich terrestrial ecosystem in the world (Hoorn et al. 2010). Biodiversity studies in North West Amazon forests have focused mainly on plants, especially tree species (Gentry 1988a; Duivenvoorden 1996; Pitman et al. 2001; Condit et al. 2002) and revealed that these forests hold a very high number of plant species (Gentry 1988a; Valencia et al. 1994; Rudas and Prieto 1998; Ter Steege et al. 2003; Duque 2004; Hoorn et al. 2010). Despite this extensive plant and animal biodiversity, the region is not yet recognized as a biodiversity hotspot (Myers et al. 2000) (http://www.biodiversityhotspots.org/xp/Hotspots/hotspots_by_region/Pages/default.aspx December 2009). The study of fungal biodiversity in tropical lowland rain forests is urgent as these are rapidly decreasing due to deforestation (Brown et al. 2006). It is estimated that the rain forest area is disappearing with an estimated 1 million square kilometers lost every 5-10 years, and this will significantly impact our knowledge of their biodiversity (Pimm and Raven 2000; Wright and Mueller-Landau 2006; Gibbs et al. 2010). For these reasons, biodiversity studies from the still existing rain forests are urgently required. Studies of mushroom diversity in the Amazon region have been done at a limited scale. Rolf Singer made several contributions to our knowledge of fungal biodiversity in the Neotropics and his works include studies on the influence of periodic flooding on fungal diversity in some igapó forests in Brazilian Amazonia (Singer 1988) and on fungal biodiversity of ectotrophic forests in central Amazonia (Singer et al. 1983). Most of his further contributions were taxonomic revisions of genera from different Neotropical regions, including the Amazon areas (i.e., Singer 1965, 1976). More recent works include the preparation of check lists on macrofungal diversity of Amazonian forests. For instance, 39 species of agarics were reported from explorations in the Walter Alberto Egler biological reserve near Manaus (De Souza and Aguiar 2004). Even fewer studies have explored fungal diversity in Colombian Amazonia (Franco-Molano et al. 2005; Vasco-Palacios et al. 2005).

Our studies aim to contribute to the knowledge of macrofungal biodiversity of some remarkable biota from different tropical lowland forests in Colombia. Therefore we compared the mushroom diversity in 1. forests occurring in two distantly located ( $>300 \mathrm{~km}$ ) regions, namely Araracuara and Amacayacu; 2. várzea (flood forests) and terra 
firme (non-flood) forests in Amacayacu; 3. putative regeneration stadia of forests in the Araracuara region; and 4. a putative ectomycorrhizal dipterocarp forest (Araracuara-Peña Roja).

\section{Methods}

Study area

The Amazonian region, a mosaic of forests embracing 7,989,004 $\mathrm{km}^{2}$ that holds approximately 60,000 plant species, is considered as the largest forested area and one of the most biodiverse places on earth (Ter Steege et al. 2003; Hoorn et al. 2010). In the northwestern part of the Amazon area, the forests cover $42 \%$ of the area of Colombia. Two locations near the Caquetá and Amazonas rivers were selected because of the availability of data on plant diversity, soils and climate, as well as accessibility. According to the life zone definition of Holdridge (Holdridge et al. 1971; Holdridge 1982) both areas belong to a Tropical Humid Forest. The climate is classified as equatorial superhumid without a dry season (Type Afi of Köppen 1936, cited by Duivenvoorden and Lips 1993). The average annual temperature is approximately $25^{\circ} \mathrm{C}$, the monthly precipitation over $100 \mathrm{~mm}$, and the annual average rainfall ranges approximately between 3,100 and 3,300 mm (Tobón 1999).

In the Middle Caquetá region, two places with permanent plots were studied that have been investigated before by Tropenbos Colombia researchers with respect to plant/tree composition, vegetation types, litter decomposition, soil chemistry, and so on (Fig. 1). The first site is located at the lower terrace of the Rio Caquetá near Araracuara (AR) community $\left(0^{\circ} 37^{\prime} \mathrm{S}, 72^{\circ} 23^{\prime} \mathrm{W}\right)$. The flood plain of the river dates back from the late glacial to Holocene (from 13,000 years BP to the present), whereas the low terraces of the Rio Caquetá were deposited in the middle pleniglacial period (about 65,000-26,000 years BP) (Duivenvoorden and Lips 1993). The plots studied are part of a mosaic of primary and secondary forests and agricultural fields originating from slash-and-burn agriculture (i.e. chagras) of different ages (Fig. 2). According to the classification of Duivenvoorden and Lips (1993) the vegetation on the well-drained parts of the lower terraces belongs to the Goupia glabra-Clathrotropis macrocarpa community and structurally this is a forest with a high above ground biomass. The texture of the soils in the plots varies between sandy and loamy sandy in the A horizon and change to argillic sand in the B horizon (Duivenvoorden and Lips 1993). All profiles show an accumulation of iron, but the intensity and depth vary, thus indicating differences in drainage. In general the soils are poor in nutrients (Vester 1997). Near Araracuara (AR) six $10 \times 40$ m permanent plots established by Vester (1997), who explored the structural aspects of the forests, were studied with respect to macrofungal diversity. Data on tree species composition, tree biomass, forest architecture and soil characteristics were taken from his studies (Vester 1997; Vester and Cleef 1998). Next to a mature forest (AR-MF), the plots represented different regeneration stages, namely 18-year old (AR-18y), 23-year old (AR-23y), 30-year old (AR-30y), 42-year old (AR-42y) and a recently slashed and burned plot that was one-year old (AR-1y) (Fig. 2). Unfortunately, the primary forest plot as selected by Vester was changed into a chagra at the onset of our investigations and became AR-1y that represented the most disturbed situation. Hence, we selected a new primary forest plot (AR-MF) during the second visit to AR.

Another forest in the Middle Caquetá region was located near the village of Peña Roja (AR-PR) and comprised a mature forest located about $50 \mathrm{~km}$ downstream from the 


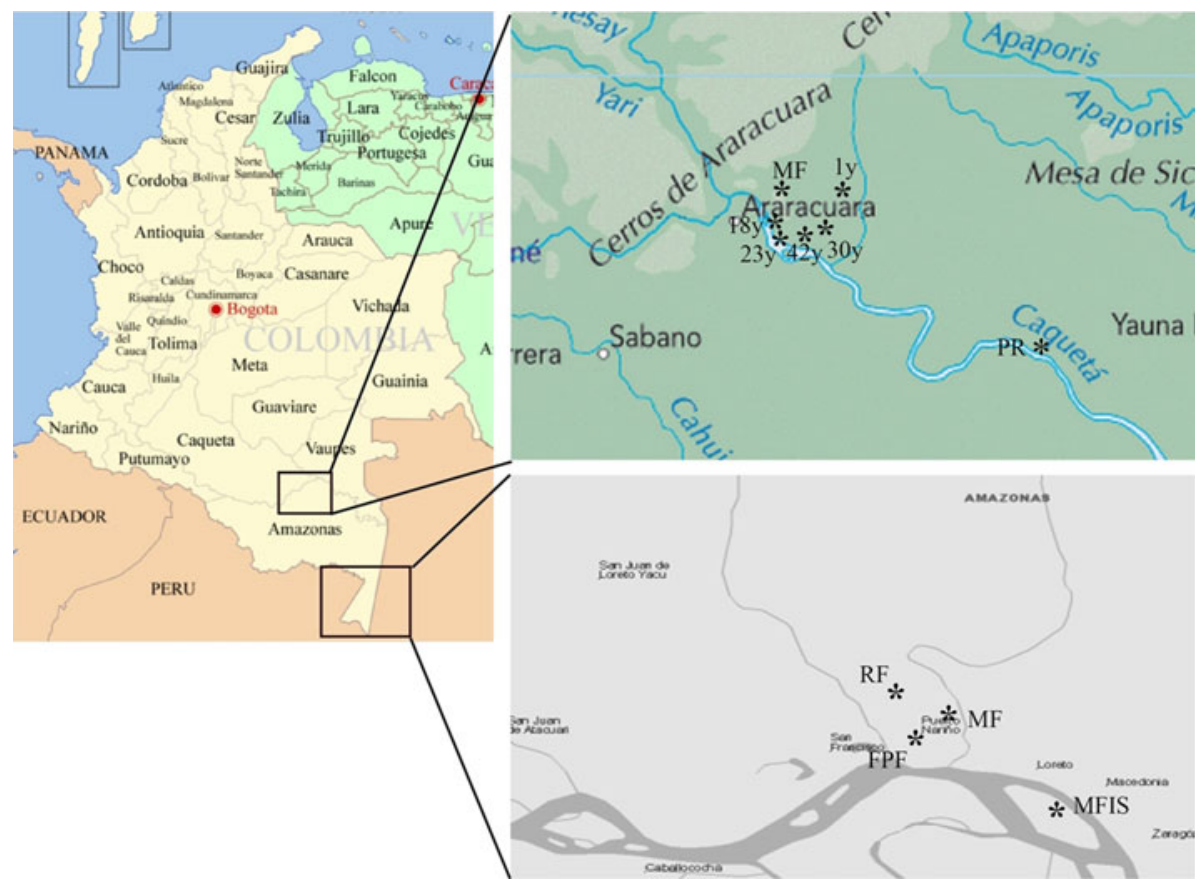

Fig. 1 Location of the plots studied in Caquetá and Amazonas departments in Colombian Amazonia. For the Araracuara site: AR-MF is a fragment of a mature forest, AR-1y belongs to a 1 year-old chagra, AR-18y is an 18-year old forest, AR-23y a 23 year-old forest, AR-30y a 30 year-old forest, and AR-42y is a 42 yearold forest and AR-PR is an upland mature forest dominated by Pseudomonotes tropenbosii (Dipterocarpaceae). For the Amacayacu site: AM-FPF is a flood plain forest close to the Amazonas River, AM-MF is a mature forest, AM-MFIS is a mature forest located in a flooding area at Mocagua Island in the Amazonas River, close to the Natural Park Amacayacu and AM-RF is a regeneration forest of ca. 36 year-old. The maps are adapted from Google maps (www.maps.google.nl)

Araracuara region along the Rio Caquetá, $00^{\circ} 34^{\prime} \mathrm{S}, 79^{\circ} 08^{\prime} \mathrm{W}$, at $200-300 \mathrm{~m}$ altitude (Fig. 1). This is a tertiary sedimentary plain with an average altitude of $60 \mathrm{~m}$ above the river level forming an undulating and highly dissected landscape. Soils are deep and well drained and classified as typical Kandiudults (Duivenvoorden and Lips 1995). They are loose and sandy at the surface and become clayey with depth. The vegetation corresponds to a mixed forest with a canopy height of 25-30 m (Londoño 2011; Londoño et al. 1995). The plant species diversity is high with 700 species of vascular plants (i.e., herbs, ferns, shrubs, palms, lianas and vines) per hectare. Pseudomonotes tropenbosii Londoño et al., a putative ectomycorrhizal tree species belonging to the ectomycorrhizal tree family Dipterocarpaceae (Smits 1994; Tedersoo et al. 2007), occurred here (Londoño et al. 1995). In this dipterocarp forest a $1,000 \mathrm{~m}^{2}$ permanent plot was established during the early $1990 \mathrm{~s}$ by scientific explorations of Tropenbos Colombia researchers and was investigated here for macrofungal diversity and productivity. Information on plant diversity as collected by Londoño and Alvarez (1997) was used in our analyses.

The second site is located in the National Park Amacayacu (AM) (Fig. 1) that was established as a national park in 1975 and covers 293,500 ha of protected area. The plots are located in the southern part of the park $\left(3^{\circ} 25^{\prime} \mathrm{S}, 70^{\circ} 08^{\prime} \mathrm{W}\right)$ and are covered by relatively well preserved forests. In areas near the local communities, where slash and burn 

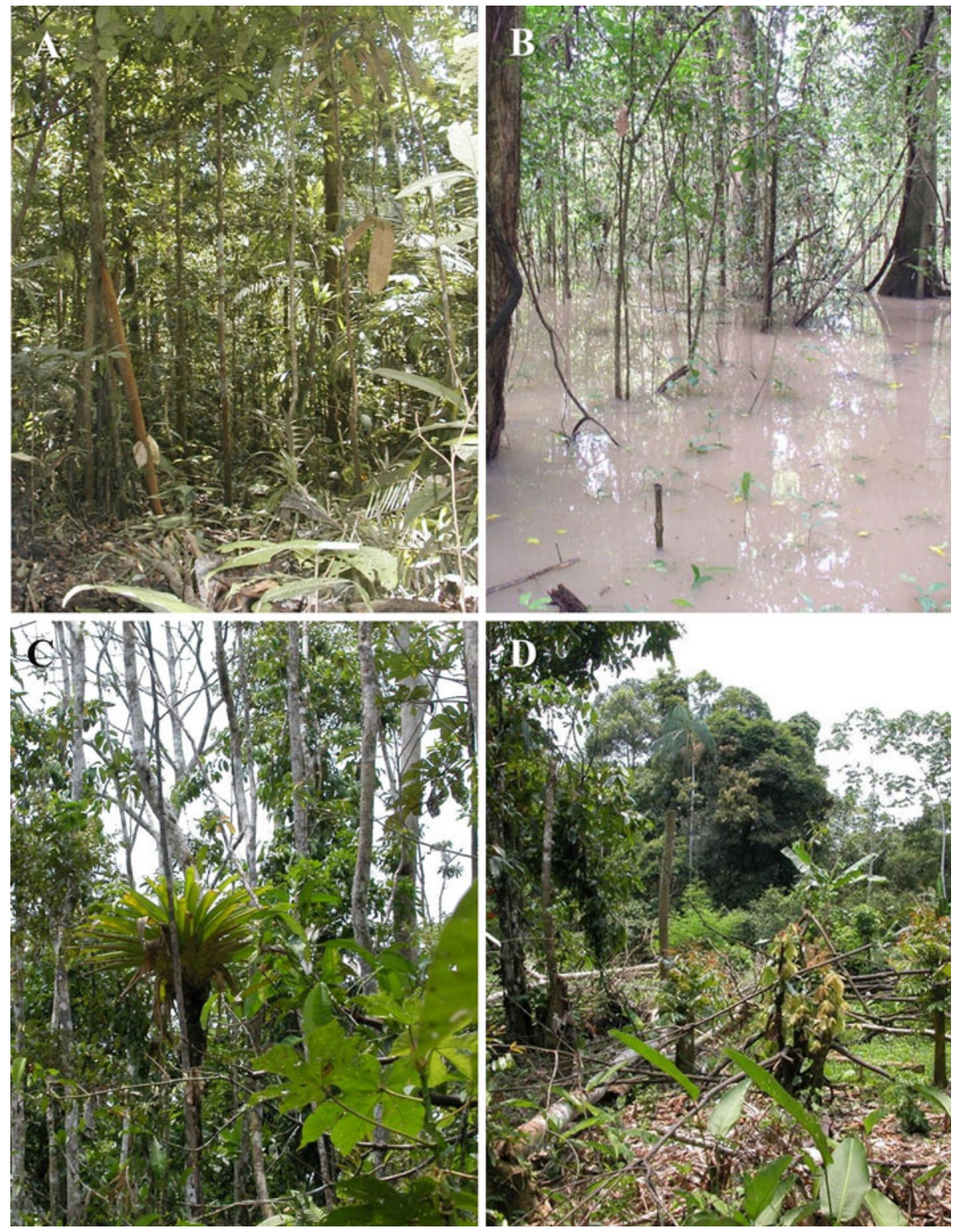

Fig. 2 Photographs of some of the forest types studied in Colombian Amazonia. a Thirty year-old forest in Araracuara (AR-30y); b Flood plain forest in Amacayacu (AM-FPF); c Regeneration forest in Amacayacu (AM-RF); d One year-old chagra in Araracuara (AR-1y). Note the many cut down trees present in the latter plot

agricultural systems (i.e. chagras) are used, a series of successional forests occur where the families Flacourtiaceae, Clusiaceae, Leguminosae, Moraceae, Rubiaceae and Violaceae are the most diverse. Approximately 1,300 plant species have been recorded in the park (Rudas and Prieto 1998). The soils have a texture between clayey to loamy-clayey, are acidic with a $\mathrm{pH}$ ranging between 4.5 and 4.9 in flood plains and between 4.1 and 4.4 in 
terra firme forests (Rudas and Prieto 1998). The Amacayacu site contains extensive lowland areas that are bordered in the south by the Amazon River and its tributaries, thus forming "várzea" (floodplains) that are subject to annual flooding with consequent soil enrichment (Fig. 2). The majority of the area is covered with "terra firme" forests. In AM, $507 \mathrm{~m}^{2}$ sized plots comprising three subplots of $13 \times 13 \mathrm{~m}$ were selected in four types of forests, namely flood plain forest (AM-FPF, várzea), regeneration forest (AM-RF, 36-year old terra firme), Mature Forest (AM-MF, terra firme) and a Mature Forest located at Mocagua Island (AM-MFIS, várzea). Due to the patchiness of the forests, the subplots could not always be realized next to each other, but were selected as close to each other as possible in apparently homogeneous remnants of forests. The AM plots were visited six times from August 2003 until October 2005, and preferably in or just after the rainy season.

\section{Sampling}

Macrofungi in all AR plots were recorded during 6 or 7 visits during a three and a half year-period (January 1998 to July 2001), while the AM plots were explored 5 or 6 times during 3 years (August 2003 to October 2005). Each plot was preferably visited in or just after the rainy season as it is well documented that this strongly benefits sporocarp production (Henkel et al. 2005). The sampling efforts took 2 weeks per visit on average. The following definitions were used: sporocarp is mushroom; collection represents the sporocarps of a species that are collected at a site at a time point, and that supposedly, represented a single 'mycelium/individual'; record is the number of sporocarps of a species in a sample at a time point; sample is the assemblage/community at a site/plot at a time point; productivity (=total abundance) is the total number of sporocarps of a species or of the assemblage/community at a site at a time point. During each visit a representative number of sporocarps of each morphological species was collected, photographed in situ when possible, packed in waxed paper, and transported in a basket for further processing. They were described and preserved according to protocols given by Largent (1986) and Lodge et al. (2004). Morphological identification of specimens was carried out with the use of keys and, in some cases, in collaboration with specialists. Throughout the studies we used the morphological species concept, which may provide an underestimation of the actual number of species present. Fungal nomenclature followed the 10th edition of the Dictionary of the Fungi (Kirk et al. 2008). All specimens collected are preserved in herbarium HUA (Medellín, Colombia, Suppl. Table 1). In addition, the number of sporocarps, their habitat and substrates were recorded. The macrofungi were found to occur on nine substrates, namely soil, trunk (diameter $>2.5 \mathrm{~cm}$ ), twigs (diameter $<2.5 \mathrm{~cm}$ ), living trees, fallen leaves, fruit shell, trash produced by ants, termite nests, and insects.

Data on plant diversity present in the AR and AR-PR sites were taken from Vester (1997; Vester and Cleef 1998) and Londoño and coworkers (1995, Londoño and Alvarez 1997), respectively. Because the above mentioned plant inventories were made some time ago, we performed a new inventory of the tree biodiversity in the Araracuara (except ARPR), and the Amacayacu plots by listing the presence of trees with a diameter at breast height $(\mathrm{DBH})$ equal or thicker than $2.5 \mathrm{~cm}$ (Suppl. Table 2). Plant nomenclature followed Mabberley's Plant Book (Mabberley 2008).

Statistical analysis

Species accumulation curves, rarefaction and analysis of shared species (Schmit and Lodge 2005) were used to analyze macrofungal species diversity between and within areas and 
plots, and between várzea (i.e., flood) and terra firme (i.e., non-flood) forests in Amacayacu. The number of species shared among plots and the Sørensen similarity index (SSI) were calculated with 'EstimateS' (EstimateS Version 8.0.0, Colwell 2006) (www.purl. oclc.org/estimates). The number of shared species between plots of the same site is expected to be higher than the numbers shared between plots from different sites. It is also expected that the number of shared species depends on the total number of species. Shared numbers 'within' a site and shared numbers 'among' sites were compared reciprocally, thus taking 'bias' by any difference in total species richness between sites into account. The significance of the different numbers of shared species was analyzed by the nonparametric Mann-Whitney $U$ test. Biodiversity similarity comparisons of the macrofungal and plant biodiversity were further made by cluster analysis using average linkage of a matrix of similarities with SPSS (SPSS 14.0.0 for Windows). Species rank numbers were obtained with SPSS, a package that provides for the calculation of average rank of ties, and abundance was plotted against rank. Rank-abundance graphs were used to analyze variation in species richness and species abundances in and between plots and regions. We modified the 'Sample based' rarefaction method (Gotelli and Colwell 2001), and applied a 'Record based' rarefaction using 100 randomizations of records, in which a record represents all sporocarps of a species present at a certain space/time combination, and taking medians over randomizations using Microsoft Office (MS Excel). The advantage of this method is that information on patchiness is maintained and it provides for a good resolution with small jumps on the $x$ - and $y$-axis.

Rainfall data from the airport in Leticia (ca. $75 \mathrm{~km}$ distance from Amacayacu park; www.tutiempo.net/en/Climate/Leticia_Vasquez_Cobo/803980.htm) were used to compare data on species richness and sporocarp formation with rainfall during the months of collection in the AM plots. This could only be done for four visits because of lack of complete weather reports for the two other visits.

\section{Results}

\section{Macrofungal biodiversity}

A total of 403 macrofungal morphospecies belonging to 129 genera and 48 families of basidiomycota and ascomycota were observed in a total of 888 collections (see Suppl. Table 1, Fig. 3). Approximately $48 \%$ of them (i.e. 194) could be identified to species level, 197 (approx. $49 \%$ ) were classified as a morphospecies belonging to some genus, and 12 (approx. $3 \%$ ) were classified as a morphospecies belonging to some family. Three families, namely Polyporaceae, Marasmiaceae and Agaricaceae were present in all 11 plots studied, but 14 families were observed to occur in just one plot. A high macrofungal biodiversity was observed in some of the Araracuara sites. The dipterocarp forest at AR-PR yielded 89 species and AR-42y 79 species, which was followed by AR-1y (51 species) that represented the most disturbed situation because the plot was made just after cutting down and burning of the forest. In contrast, the mature forest (AR-MF) showed a low number of 32 macrofungal species. Forty six species were reported exclusively from the dipterocarp forest (AR-PR) (Fig. 4) and 10 of them belonged to putative ectomycorrhizal genera, such as Amanita (2 spp.), Austroboletus (1 sp.), Boletus (2 spp.), Lactarius (3 spp.) and Russula (2 spp.) (see Suppl. Table 1).

Species accumulation curves are increasing for the plots from all forests sampled in the two regions (Fig. 5), thus indicating that we sampled the mushroom biota only partially. 

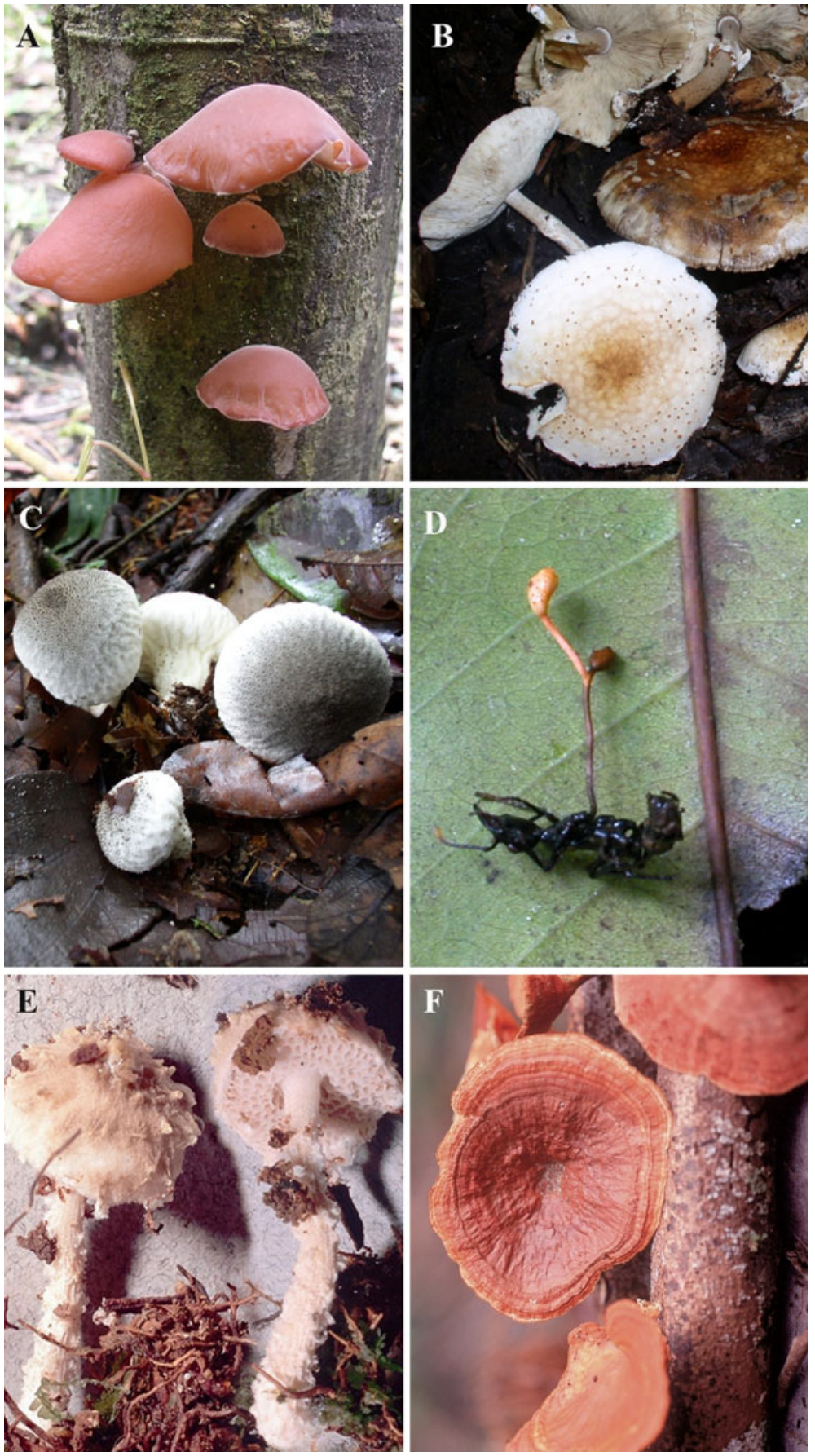

Fig. 3 Photographs of some macrofungi from the forests studied in Colombian Amazonia. a Auricularia fuscosuccinea growing on standing trunk; b Lepiota hemisclera growing on soil; c Lycoperdon sp 1. growing on leaf litter; d Cordyceps sp 1. growing on ant; d Austroboletus sp. nov. from dipterocarp forest; E. Pycnoporus sanguineus growing on dead tree trunk 


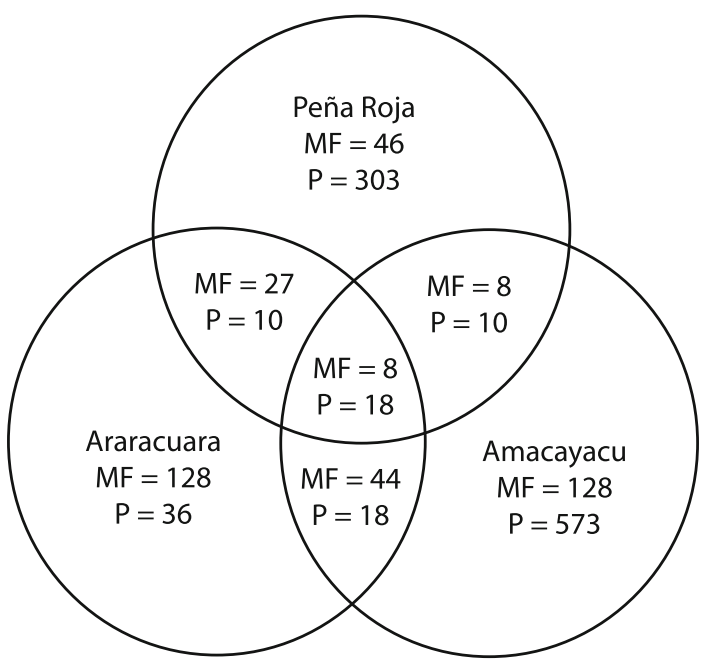

Fig. 4 Venn diagram showing the total number of macrofungal and plant species in the Amazon lowland forests investigated from two regions in the Colombian Amazon. The Peña Roja forest (AR-PR) is represented here as a separate circle because of the putative ectomycorrhizal nature of this forest. The abundance of Pseudomonotes tropenbosii (Dipterocarpaceae) seems a main determinant for the macrofungal diversity of this plot. Inside the circles the number of fungal and plant species is indicated for each region and forest type. The data in the circle curves represent the number of macrofungal and plant species at each locality, whereas those indicated in the shared parts of the circle curves indicate the number of species shared between the regions. $M F$ number of macrofungal species; $P$ number of plant species with diameter at breast height $>2.5 \mathrm{~cm}$

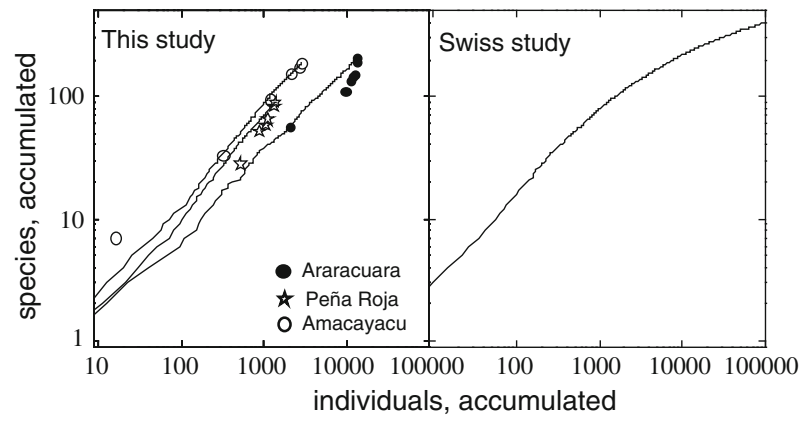

Fig. 5 Accumulation graphs of the macrofungal species in Araracuara, Peña Roja and Amacayacu showing the increase of species after the collection trips (left panel). The dots represent the real (overall) data, whereas the lines are based on 'record based rarefaction' with 100 randomizations of records in which a record represents all sporocarps of a species at a certain space/time combination (i.e., a sample). The advantage of this method is that information on patchiness is maintained and the 'record based' rarefaction provides sufficient resolution leaving small jumps on the $x$ - and $y$-axis. For comparison the randomization results of a study in a temperate Swiss forest (Straatsma et al. 2001) are added (right panel)

This questions whether we sampled sufficiently to allow meaningful comparisons of the data collected in the two regions. The number of species shared between the AR, AR-PR and AM plots is presented in Tables 1 and 2 and Fig. 4. It can be clearly seen that the number of shared species within the AR and AM plots is higher than between the two sites (Table 1). The number of shared species among AR plots, excluding AR-PR, ranged from 
Table 1 Shared macrofungal species between plots in Araracuara and Amacayacu

\begin{tabular}{|c|c|c|c|c|c|c|c|c|c|c|c|}
\hline & \multicolumn{7}{|c|}{ Araracuara } & \multicolumn{4}{|c|}{ Amacayacu } \\
\hline & $\begin{array}{l}\text { AR- } \\
42 y\end{array}$ & $\begin{array}{l}\text { AR- } \\
30 y\end{array}$ & $\begin{array}{l}\text { AR- } \\
23 y\end{array}$ & $\begin{array}{l}\text { AR- } \\
18 y\end{array}$ & $\begin{array}{l}\text { AR- } \\
1 y\end{array}$ & $\begin{array}{l}\text { AR- } \\
\text { MF }\end{array}$ & $\begin{array}{l}\text { AR- } \\
\text { PR }\end{array}$ & $\begin{array}{l}\text { AM- } \\
\text { FPF }\end{array}$ & $\begin{array}{l}\text { AM- } \\
\text { MF }\end{array}$ & $\begin{array}{l}\text { AM- } \\
\text { MFIS }\end{array}$ & $\begin{array}{l}\mathrm{AM}- \\
\mathrm{RF}\end{array}$ \\
\hline AR- $42 y$ & 79 & 16 & 13 & 14 & 12 & 9 & 12 & 9 & 6 & 3 & 7 \\
\hline AR-30y & 16 & 43 & 7 & 10 & 3 & 6 & 11 & 4 & 4 & 3 & 5 \\
\hline AR-23y & 13 & 7 & 42 & 5 & 2 & 4 & 10 & 3 & 5 & 2 & 5 \\
\hline AR-18y & 14 & 10 & 5 & 41 & 3 & 5 & 15 & 3 & 1 & 4 & 5 \\
\hline AR-1y & 12 & 3 & 2 & 3 & 51 & 8 & 5 & 8 & 3 & 6 & 3 \\
\hline AR-MF & 9 & 6 & 4 & 5 & 8 & 32 & 9 & 5 & 2 & 3 & 6 \\
\hline AR-PR & 12 & 11 & 10 & 15 & 5 & 9 & 89 & 5 & 4 & 4 & 5 \\
\hline $\begin{array}{l}\text { AM- } \\
\text { FPF }\end{array}$ & 9 & 4 & 3 & 3 & 8 & 5 & 5 & 63 & 12 & 14 & 8 \\
\hline $\begin{array}{c}\text { AM- } \\
\text { MF }\end{array}$ & 6 & 4 & 5 & 1 & 3 & 2 & 4 & 12 & 66 & 11 & 22 \\
\hline $\begin{array}{l}\text { AM- } \\
\text { MFIS }\end{array}$ & 3 & 3 & 2 & 4 & 6 & 3 & 4 & 14 & 11 & 50 & 8 \\
\hline AM-RF & 7 & 5 & 5 & 5 & 3 & 6 & 5 & 8 & 22 & 8 & 64 \\
\hline
\end{tabular}

The total number of species per plot is indicated in bold and italics

2 to 16, within AM from 8 to 22 and between AR and AM from 1 to 9. Using the nonparametric Mann-Whitney $U$ test, differences in shared species between AR and AM were found to be highly significant $(p=0.014$ when comparing the relatively species rich AM plots with the relatively species poor AR plots, and $p=0.003$ when comparing AR with AM). Due to the aberrant plot size and the putative ectomycorhizal nature the AR-PR plot was not considered in this analysis, but 5-15, and 4 and 5 shared species occurred between AR-PR and AR and AM plots, respectively. In Amacayacu, the number of species shared by plots in terra firme forests was found to be significantly different from those occurring in the flood forests (várzea) (Table 2) $(p=0.028$ when comparing the relatively species rich terra firme plots with the relatively species poor várzea plots, and $p<0.001$ for the reciprocal comparison). Thus our sampling efforts revealed significant differences in macrofungal biodiversity between the Araracuara and Amacayacu regions, and between várzea and terra firme forests in the Amacayacu region. Cluster analysis provides for a more detailed illustration of these patterns. Two main clusters for macrofungal species composition appeared (Fig. 6a). One group comprised the Amacayacu plots and the other represented those from Araracuara. The latter formed two subclusters, namely one comprising plots AR-18y, AR-23y, AR-30y, AR-42y and AR-PR, and a second one with the most disturbed plot (AR-1y) and the primary forest plot (AR-MF). In the first subcluster all plots, except AR-PR, corresponded to patches of forests that varied in age between 18 and 42 years of regeneration after the chagras were abandoned. The analysis of the Amacayacu plots yielded two subclusters with one containing the terra firme forests (AM-MF and AM$\mathrm{RF}$ ) occurring on the high terraces, and the other consisting of plots located in flooded areas (AM-FPF and AM-MFIS) (Fig. 6a).

One hundred and twenty eight species were found in both the AR and AM plots. Forty four species were found to occur in both regions and eight occurred in AM and AR including AR-PR (Fig. 4). The number of fungal families was 47 in the Araracuara plots and ranged from 14 in AR-23 and AR-MF to 24 in AR-1y and AR-PR. In AM, 34 families 
Table 2 Shared species between plots and subplots from terra firme and várzea forests in Amacayacu

\begin{tabular}{|c|c|c|c|c|c|c|c|c|c|c|c|c|}
\hline & \multicolumn{6}{|c|}{ Terra firme } & \multicolumn{6}{|c|}{ Várzea } \\
\hline & \multicolumn{3}{|c|}{ AR-MF subplots } & \multicolumn{3}{|c|}{ AM-RF subplots } & \multicolumn{3}{|c|}{ AM-FPF subplots } & \multicolumn{3}{|c|}{ AM-MFIS subplots } \\
\hline & 1 & 2 & 3 & 1 & 2 & 3 & 1 & 2 & 3 & 1 & 2 & 3 \\
\hline \multicolumn{13}{|c|}{ AM-MF } \\
\hline 1 & 21 & 6 & 4 & 5 & 5 & 6 & 2 & 0 & 3 & 3 & 4 & 2 \\
\hline 2 & 6 & 27 & 3 & 5 & 8 & 6 & 4 & 2 & 3 & 2 & 3 & 3 \\
\hline 3 & 4 & 3 & 29 & 8 & 5 & 4 & 1 & 1 & 2 & 2 & 1 & 1 \\
\hline \multicolumn{13}{|c|}{ AM-RF } \\
\hline 1 & 5 & 5 & 8 & 29 & 7 & 9 & 1 & 1 & 1 & 3 & 1 & 1 \\
\hline 2 & 5 & 8 & 5 & 7 & 26 & 8 & 2 & 2 & 3 & 3 & 3 & 2 \\
\hline 3 & 6 & 6 & 4 & 9 & 8 & 28 & 4 & 2 & 2 & 5 & 5 & 2 \\
\hline \multicolumn{13}{|c|}{ AM-FPF } \\
\hline 1 & 2 & 4 & 1 & 1 & 2 & 4 & 27 & 2 & 4 & 3 & 4 & 4 \\
\hline 2 & 0 & 2 & 1 & 1 & 2 & 2 & 2 & 18 & 3 & 4 & 2 & 1 \\
\hline 3 & 3 & 3 & 2 & 1 & 3 & 2 & 4 & 3 & 26 & 1 & 3 & 4 \\
\hline \multicolumn{13}{|c|}{ AM-MFIS } \\
\hline 1 & 3 & 2 & 2 & 3 & 3 & 5 & 3 & 4 & 1 & 20 & 5 & 3 \\
\hline 2 & 4 & 3 & 1 & 1 & 3 & 5 & 4 & 2 & 3 & 5 & 20 & 3 \\
\hline 3 & 2 & 3 & 1 & 1 & 2 & 2 & 4 & 1 & 4 & 3 & 3 & 21 \\
\hline
\end{tabular}

The total number of species per plot is indicated in italics

A

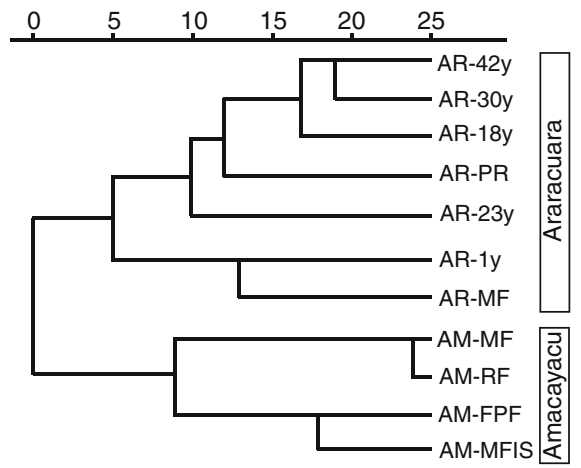

B

\begin{tabular}{lllll}
0 & 5 & 10 & 15 & 20 \\
\hline
\end{tabular}

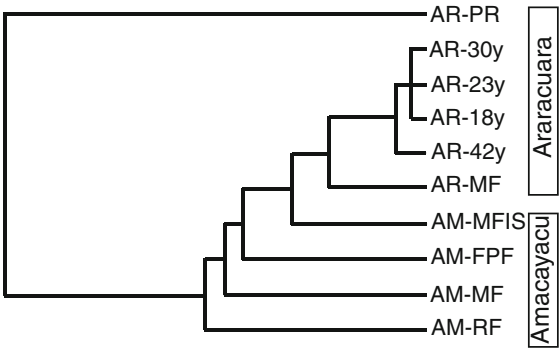

Fig. 6 Cluster analysis of macrofungal (a) and plant species (b) composition using average linkage between groups from seven plots at the Araracuara site ( $A R-M F$ mature forest, $A R-1 y 1$ year-old, $A R-18 y$ 18 year-old, $A R-23 y 23$ year-old, $A R-30 y 30$ year-old, $A R-42$ y 42 year-old, $A R-P R$ Peña Roja) and four plots from the Amacayacu site $(A M-F P F$ flood plain forests/varzea, $A M-M F$ mature forest/terra firme, $A M-M F I S$ mature forest at Island/varzea, $A M-R F$ regeneration forest/terra firme)

occurred, which is less than that of Araracuara (Table 3). The highest number of species $(n=66)$ occurred in the mature terra firme forest (AM-MF) and the lowest number of species $(n=50)$ was observed in the várzea mature forest on the island (AM-MFIS) (Table 3). Eighteen species were shared between terra firme plots (AM-MF, AM-RF; 


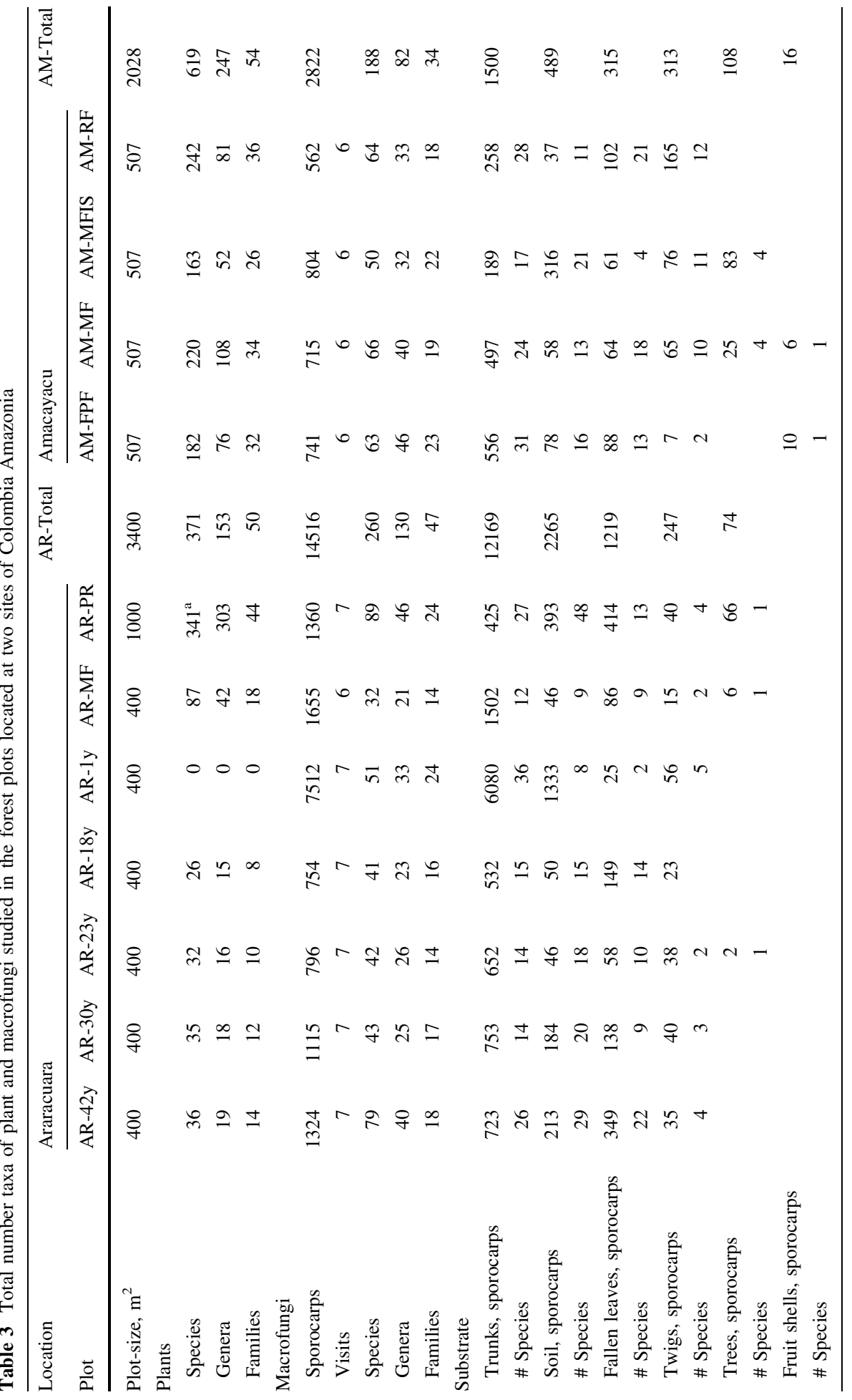




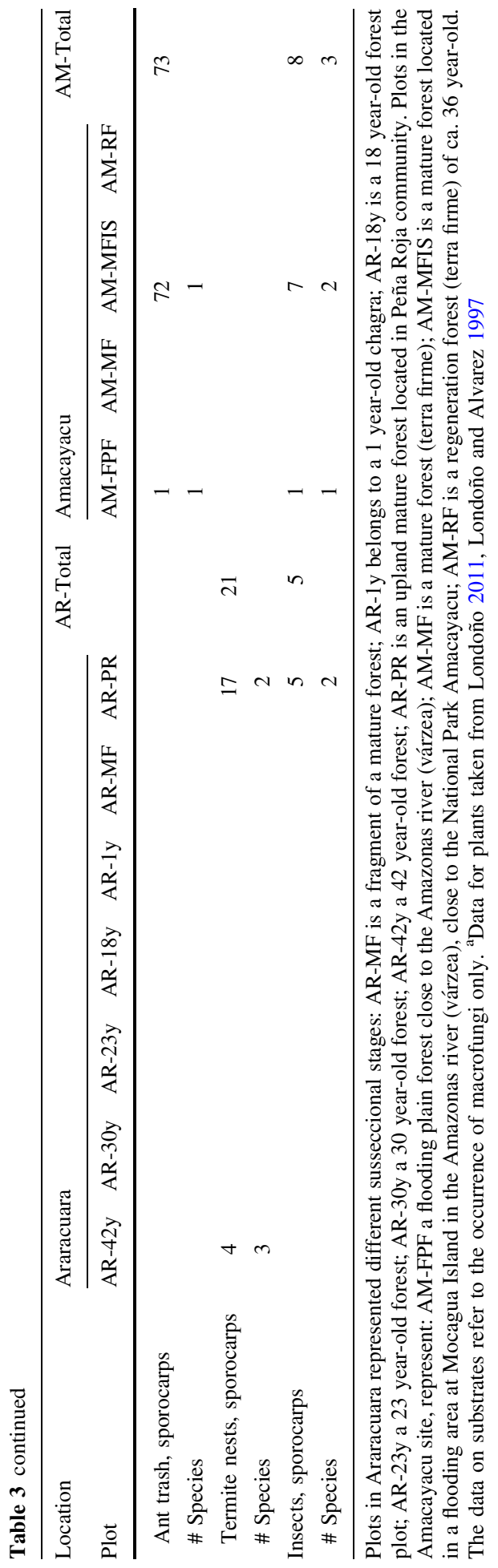


SSI $=0.338$ ), and nine species occurred in the forest plots on the flood plains (AM-MFIS, AM-FPF; SSI = 0.246). Fifty one species occurred in the plots occurring on flood plains (AM-FPF or AM-MFIS), but only four species (viz. Agaricus sp. 2, Auricularia fuscosuccinea, A. delicatula and Clavaria sp. 1) were found to be shared between them. Thirty species occurred in the flood plain forest (AM-FPF) only. No species were found to be shared between the mature forest plots located in the two Amazonian regions studied. Thirty two species occurred exclusively in the two mature forests studied (viz., AM-MF and AR-MF), 28 of these were recorded in the mature forest in Amacayacu (AM-MF) and four species in the mature forest plot in Araracuara (AR-MF). Nineteen species, most of them belonging to the artificial group of aphyllophorales, occurred in the most disturbed plot (AR-1y) only. These species included Cymatoderma sclerotioides, Funalia polyzona, Hexagonia tenuis, Hydnellum sp., Lentinus strigellus, L. strigosus, L. swartzii, Podoscypha brasiliensis and Polyporoletus sublividus.

The number of species found exclusively in plots representing putative successional stages of the forests was relatively low. For instance, in AR-18y 20 unique species occurred. Species like Collybia sp. 4, Entoloma cystidiophorum and Trametes modesta were found in all successional plots located in Araracuara (viz., AR-18y, AR-23y, AR-30y and AR-42y) and they may be considered as generalists. In contrast, the 36-year old forest plot in Amacayacu (AM-RF) contained 51 unique species. Nine species, including Marasmius leoninus, M. haematocephalus, Podoscypha aff. brasiliensis, Polyporus guianensis and Tetrapyrgos nigripes, were shared between AM-RF and at least one of the successional forest plots in Araracuara.

The presence of sporocarps of macrofungi is strongly influenced by seasonality. Unfortunately, our dataset does not allow for a thorough analysis of seasonality aspects. However, some general remarks can be made. In general, higher numbers of sporocarps were found in the AR plots in periods just after high precipitation, e.g. January 1998 (74 species with 2,051 sporocarps counted for all AR plots) or June 1998 (116 species with 6,884 sporocarps for all AR plots). Because no detailed weather data were available for the AR plots no inferences about a relationship between precipitation and sporocarp formation could be made. Available but limited data on the amounts of precipitation from Leticia airport that is located approximately $75 \mathrm{~km}$ from the AM plots, showed that in terra firme forests (AM-MF, AM-RF) the number of species and sporocarps was highest during periods with approximately $200 \mathrm{~mm}$ rainfall per month and lower during periods with approximately 50 and $400 \mathrm{~mm}$ rainfall per month (Fig. 7a, b). In AM-FPF, a flood forest plot (várzea), the number of species and sporocarps was highest in the wettest period (400 mm rainfall per month), whereas for the other várzea plot (AM-MFIS) a somewhat erratic pattern emerged (Fig. 7a, b). It is important to note, however, that this latter plot was completely flooded during this wettest period. Polyporoid and stereoid species, like Stereopsis hiscens and Polyporus tenuiculus, as well as the ascomycete Cookeina tricholoma were recorded 6 or 7 times during 13 visits, and the formation of sporocarps by these species seems less influenced by the weather conditions.

\section{Macrofungal abundance and productivity}

The total number of sporocarps observed in this study was 17,338. A high number of sporocarps $(n=14,516)$ was collected at the Araracuara site, mainly in the most disturbed plot (AR-1y, 7,512 sporocarps), while for all four Amacayacu plots 2,822 sporocarps were counted (Table 3$)$. Forty three percent $(n=177)$ of the species showed a low production of sporocarp formation (i.e., less than five sporocarps); $45 \%$ of the species $(n=198)$ 
A

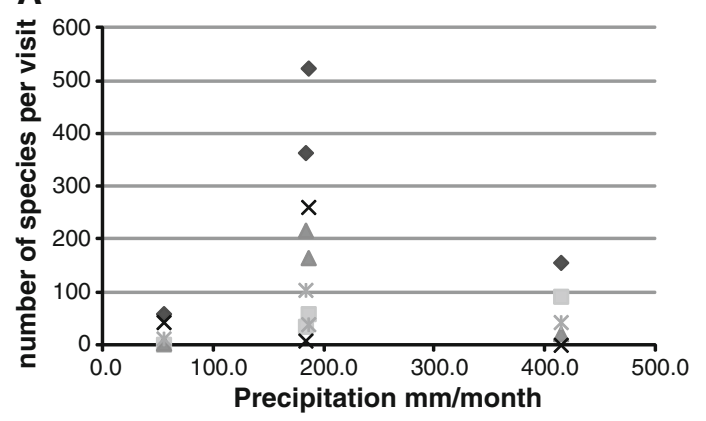

B

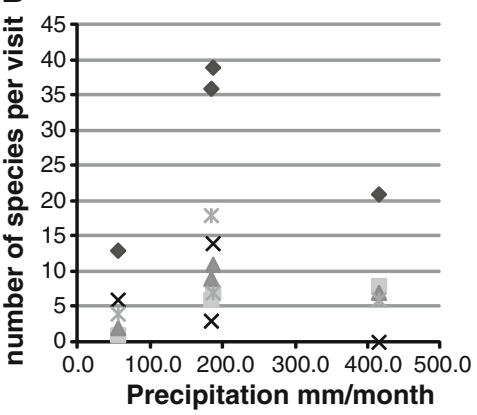

- All plots AM-FPF várzea $\triangle$ AM-MF terra firme XAM-MFIS várzea ※AM-RF terra firme

Fig. 7 Number of species (a) and sporocarps (b) in four Amacayacu plots during four visits with different amounts of precipitation. One visit (August 2003) took place in a relative dry period ( $55 \mathrm{~mm} / \mathrm{month})$, two (December 2003, April 2005) in moderately wet periods (approximately $185 \mathrm{~mm} / \mathrm{month}$ ), and one (October $2005)$ in a wet period $(415 \mathrm{~mm} / \mathrm{month}$

Fig. 8 Rank-abundance curves for two plots with different fungal diversity located in Araracuara. Graphs were constructed using the number of species ranked ( $X$-axis) against their abundance ( $Y$-axis). AR-42y is representative for those plots in different regeneration stages (i.e., AR-18y, AR-23y, AR-30y and AR-42y old plots) and AR-1y is representative for the Araracuara mature forest (AR-MF) and the recently slash and burned plot (AR-1y)

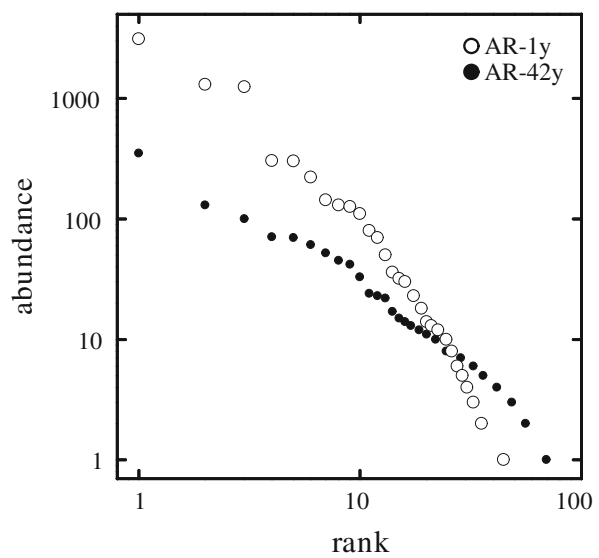

formed between 5 and 100 sporocarps, and $6.6 \%(n=27)$ of the species produced more than 100 sporocarps. Cookeina tricholoma ( $n=3,157$ sporocarps), Lepiota sp. 2 ( $n=1,301$ sporocarps) and Pycnoporus sanguineus ( $n=2,343$ sporocarps) belonged to this latter category, followed by the 11 Lentinus species that produced a total of 1,039 sporocarps. It is interesting to note that these latter species occurred mainly in the youngest and most disturbed plot (AR-1y) where they grew on trunks and twigs. The 44 species of the genus Marasmius produced a total of 1,091 sporocarps.

Rank-abundance graphs made for two plots in Araracuara, viz., AR-1y, the richest in sporocarps (7,494 sprorocarps representing 51 species) and AR-42y, the richest in species (1,324 sporocarps, 79 species; Fig. 8) showed more or less regular patterns. This means that plots with a high total number of sporocarps hold not just one species that is very productive in sporocarp formation, but several ones and that high numbers of sporocarps are not just due to one outlying species in particular. Productivity and species richness varied in space (plots) and time (visits) (Fig. 5). It seems, however, that the species in the 
AR plots accumulated somewhat slower than those in AR-PR and AM, which may be due to the presence of the highly productive, but moderately species-rich plots AR-MF and AR-1y.

\section{Substrate utilization}

The highest production of sporocarps was observed on trunks and soil. The trunk substrate yielded the most diverse and productive macrofungi in all plots. One hundred and eight species that formed 13,669 sporocarps were reported from this substrate, with 12,169 sporocarps in AR and 1,500 in AM. In the most disturbed plot AR-1y, species that produced high numbers of sporocarps on trunks (Table 3) were dominant. These included Pycnoporus sanguineus, Cookeina tricholoma, and species of Lentinus. The second most diverse and productive substrate was soil, with 156 species that produced 2,754 sporocarps. On the fallen leaves substrate we found 1,534 sporocarps, mostly from species of Marasmius; 560 sporocarps were recorded on twigs, and the lowest productivity was noted for fungi that grew on insects belonging to the families Fulgoridae, Hemiptera, Hymenoptera and Coleoptera and on which only 13 sporocarps were observed. Occasionally, sporocarps were found on fruit shells and trash from ants in the AM sites, and on a termite nest in the AR sites. Substrate utilization differed between the sites. In AR-PR a high number of species occurred on soil $(n=48)$, whereas AR-1y had 36 species on trunks, but this plot showed the lowest number of species on soil and fallen leaves. In the Amacayacu plots the highest diversity was found on trunks with 75 species and 1,500 sporocarps. The terra firme plots AM-MF and AM-RF had relative high numbers of species on fallen leaves (18 and 21 species, respectively, Table 3).

\section{Tree biodiversity}

One thousand and thirty-five specimens of trees with a dbh (diameter at breast height) $\geq 2.5 \mathrm{~cm}$ were identified. These belonged to 632 species and 77 families. The highest number of species was reported from AR-PR $(n=341)$ (Londoño and Alvarez 1997), followed by AM and AR forest plots (Fig. 4; Table 3, Suppl. Table 2). However, one needs to take into consideration that the plots studied differed in size (see 'Materials and methods'). When the plots in Amacayacu and Araracuara, excluding AR-PR, are compared, $35(32.7 \%)$ plant species occurred in two plots, $13(15.8 \%)$ were present in three plots, three species (3.6 \%), viz., Garcinia macrophylla, Miconia sp. 3 and Neea divaricata were identified from four plots, and Clathrotropis macrocarpa and Inga sp. 2 were observed in six plots (see Suppl. Table 2). Within AM, biodiversity similarity between várzea forests (AM-MFIS and AM-FPF) and terra firme forests (AM-MF and AM-RF) was low (SSI 0.09), thus indicating that these two types of forests differ greatly in their plant biodiversity. The two forests occurring on the flood plains (AM-FPF and AM-MFIS) showed a low similarity value (SSI 0.216), and this was also true for those occurring in the terra firme areas (AM-MF and AM-RF, SSI 0.248). Thus, plant biodiversity differs widely between the four types of forest studied in Amacayacu. A similar comparison between the plots located at the Araracuara site showed low similarity values indicating a low number of shared plant species. From the 75 identified tree species in the Araracuara plots, only Clathrotropis macrocarpa (Leguminosae) occurred in all four successional plots (viz., AR-18y, AR-23y, AR-30y and AR-42y) and the mature forest (AR-MF). The tree species Miconia sp. was reported from four successional plots but not in the mature forest. Seven tree species (Cecropia sp. 1, Clathrotropis macrocarpa, Goupia glabra, Inga sp. 2, 
Miconia minutiflora, Miconia prasina, Miconia sp. 3) were mostly present in the early successional stages (see Suppl. Table 2), 10 species (Annonaceae sp. 4, Guatteria stipitata, Inga sp. 1, Inga sp. 3, Jacaranda cf. copaia, Lauraceae sp. 1, Moraceae sp. 5, Nectandra sp. 1, Pourouma bicolor, Swartzia sp. 1) were present in two plots only, and the remaining 54 species were restricted to one of the plots. Importantly, the putative ectomycorrhizal tree species Pseudomonotes tropenbosii (Dipterocarpaceae) showed the highest Important Value Index (IVI) of $6 \%$ in AR-PR (Londoño et al. 1995).

Cluster analysis of tree and fungal biodiversity yielded similar patterns (Fig. 6). Similar to the macrofungi (Fig. 6a), the plant species composition clustered according to the two regions (Fig. 6b). The plants from AR-PR, however, clustered differently from the pattern obtained for the fungi and seemed to be the most deviating if compared to the other AR as well as the AM plots. The ratio between macrofungi-and tree species with $\mathrm{dbh}>2.5 \mathrm{~cm}$ for all AR plots was 0.7, but varied between 1.23 and 2.19 for the regeneration stadia (AR$18 \mathrm{y}, 23 \mathrm{y}, 30 \mathrm{y}$ and $42 \mathrm{y}$ ), and was 0.37 for AR-MF. For the AM plots this ratio was 0.30 and varied from 0.26 to 0.35 . For AR-PR the value was 0.26 but this was based on all plant species that were reported by Londoño and coworkers.

\section{Discussion}

This study constitutes an analysis of macrofungal diversity from two regions in the Colombian Amazon that are separated by approximately $300 \mathrm{~km}$. The forests in North West Amazonia constitute a mosaic of different forest types with local and particular assemblages (Gentry 1988b; Tuomisto et al. 1995; Hoorn et al. 2010). Patterns in the spatial distribution of fungal species provide important clues about the underlying mechanisms that structure ecological communities and these are central to set conservation priorities (Mueller and Schmit 2007). Although microorganisms comprise much of Earth's biodiversity, little is known about their biodiversity and the function of this diversity compared to that of plants and animals (Green and Bohannan 2006). Analyses of large data sets regarding fungal biodiversity from Amazonian forests are lacking, but it seems fair to consider that the availability and quality of suitable substrates are important factors that determine patterns of distribution and species richness of fungi. Consequently, differences in taxonomic and chemical plant diversity will affect fungal diversity (Swift et al. 1979). Habitat heterogeneity offers variation in microclimates that will influence fungal species diversity and productivity (Singer 1976, Gómez-Hernández and Williams-Linera 2011). A trend of decreasing diversity of both plants and macrofungi was observed in the younger plots, except the recently established chagra (AR-1y). This plot showed a high proportion of dead wood (trunks and twigs), lacked a tree canopy and, hence, received more insolation and was more dry, and had richer soils as a result of slash and burn for agriculture (C. Lopez-Q., unpubl. data). A particular assemblage of highly productive wood-inhabiting fungal species occurred on the supply of woody substrates, including species as Pycnoporus sanguineus, Schizophyllum commune and Lentinus species that seem to form sporocarps during periods of relative drought and more intense insolation. One may wonder what may have been the cause for this sudden emergence of many sporocarps just after cutting down the trees? It seems unlikely that this is the result of fresh colonization just after the trees were cut down. A possibility may be that the wood-inhabiting species may have been present on or inside the living trees, e.g. as colonizers or as endophytes. Similar fungi have been found as endophytes in oil palms in Thailand (Rungjindamai et al. 2008; Pinruan et al. 2010). Crozier et al. (2006) observed similar basidiomycetous endophytes in 
bark of stems of the chocolate tree Theobroma cacao, and suggested that these fungi possess an asymptomatic endophytic stage that may switch to a saprotrophic stage when the host senesce. According to these authors, fungi with such flexible life styles may have temporal and spatial advantages over fungi without such flexibility. In line with these suggestions, we consider a 'endophyte to saprotroph' transition to explain the sudden emergence of these wood-inhabiting fungi after the trees were cut down a realistic scenario that needs further testing.

Formation of sporocarps strongly depends on environmental conditions, such as temperature, rainfall and humidity (Alexopoulos et al. 1996; Zak 2005). From the limited data on the possible relation between precipitation and the presence of species and the number of sporocarps formed it appears that an optimal amount of rainfall exists for the formation of sporocarps by the various species in the Colombian Amazon forests. Probably, the optimal amount of precipitation differs also between terra firme and flood forests, but more data are required to address this issue. Next to differences in plant composition and landscapes, the plots also differed in a number of abiotic factors, such as $\mathrm{pH}$, organic matter, cation exchange capacity (CEC), nutrient and mineral contents, and flooding frequencies (Vester and Cleef 1998; C. Lopez-Q. unpubl. data). Habitat differentiation, together with different perturbation stages, such as flooding and forest succession, may result in different microclimates. The observed differences in shared species between flood and non-flood forests and the high production of sporocarps in the flooded plots AM-MFIS (804 sporocarps) and AM-FPF (741 sporocarps) at the Amacayacu site may be related to the regular deposition of detritus, nutrients and organic matter during the floods that occur on average twice a year. Alluvial soils in várzea are rich in nutrient content (Singer 1988) and those in Amacayacu also have a higher $\mathrm{pH}$ of 4.5-4.9 if compared to terra firme forests that have a $\mathrm{pH}$ range of 4.1-4.4 (Rudas and Prieto 1998). The main determinant causing the differences in fungal biodiversity between flood and non-flood forests remains to be identified.

The extent of fungal diversity on a global scale is a heavily debated issue (Hawksworth 1991, 2001; Mueller et al. 2007; Schmit and Mueller 2007; Hyde 2001; Hyde et al. 2007; Crous et al. 2006). Extrapolations based on the total number of plant species and the assumption of a specific relationship between plant and fungal biodiversity have been used to get to estimates of 1.5 million or more existing species of fungi. In our case, the tree/ fungal species ratio was 0.3 for Amacayacu and 0.7 for Aracuara, which is much higher than the results obtained by Schmit and Mueller (2007) who estimated the ratio between vascular plants and macrofungal species in Central and South America as 0.08. The difference between our results and those of Schmit and Mueller may be due to the fact that we included only trees with a dbh $\geq 2.5 \mathrm{~cm}$, while they obtained the ratio using macrofungal species and all vascular plants from Central and South America. However, both ratios may underestimate the real figure of fungal biodiversity as many taxa are excluded, such as all or most microfungi, including yeasts, zygomycetes and filamentous Ascomycota. These fungi, especially the latter, form a very species rich lineage and are included in other estimates on the extent of global fungal biodiversity (e.g. Hawksworth 1991, 2001).

Species accumulation curves are frequently used to analyse biodiversity data (Schmit and Lodge 2005) and rank-abundance graphs are among the best methods to demonstrate variation in species richness and species abundances between the various plots studied and in the absence of a proper model for species abundance distributions (Magurran 2004). It is important to note that in our plots all species accumulation curves are still increasing, and hence, are not saturated. Similarly, species richness curves in tropical cloud forests in Mexico remained unsaturated (Gómez-Hernández and Williams-Linera 2011). Our 
observations suggest that many species still need to be discovered from the forest plots that we studied. Eighty six percent of the macrofungal species were found in just one of the 11 plots studied indicating a relative high level of differentiation in species composition between the plots. This was not only observed for forests from two distantly located regions (viz., Araracuara versus Amacayacu), but also for those occurring within each region. Our observations are in agreement with Lodge (1997) who noted that fungal communities in lowland forests in Ecuador can widely differ at short distances of even a few meters.

The observation that the macrofungal species composition differs between the various forest types may be a consequence of ecological specializations of the species involved. Ectomycorrhizal relationships are an example of such an ecological specialization (Alexander and Selosse 2009, Smith et al. 2011). The putative ectomycorrhizal relationship between some groups of macrofungi and Pseudomonotes tropenbosii (Dipterocarpaceae) in AR-PR constitutes an ecological variable needed to understand the observed fungal biodiversity of this forest type. All other plots apparently lacked ectomycorrhizal trees and fungi, and, therefore, this unique feature of the AR-PR plot contributed to the noted macrofungal species diversity of this forest. Singer and Aguiar (1979) emphasized that ectomycorrhizal species occur on sandy soils in the Amazon and the AR-PR plot seems to support this suggestion. The many wood-inhabiting fungi that occurred after cutting down the trees in AR-1 yr (see also above) and that seem to form sporocarps under more dry conditions are another example of a specific guild of fungi. However, the rarity of many species, expressed here as singletons in the analysis, indicates that the species richness estimators have to be interpreted with caution as they may have rather broad confidence limits as asserted by Magurran and Queiroz (2010). It is unlikely that a single model explains the patterns that influence species diversity for any group of organisms in different ecosystems. Many hypotheses resulting from meta studies explain the distribution and patterns of species richness of birds (Davies et al. 2007; Rahbek et al. 2007), vascular plants (Kreft and Jetz 2007), and plants and animals (Hawkins et al. 2007; Whittaker et al. 2007), but none of these studies took fungi into account. The number of macrofungal species on its own is not a good parameter to estimate the ecological quality of mycobiota occurring in Amazon forests. One needs to consider productivity, habitat preference and ecological interactions, such as nutrient cycling, decomposition, and ectomycorrhizal relationships (see e.g. Alexander and Selosse 2009; Braga-Neto et al. 2008; Lodge 1997; Smith et al. 2011). Moreover, the extent of their below ground diversity and functioning remains unknown from counts of sporocarps only, which provides a crude estimate for the macrofungal biodiversity at best (Lodge and Cantrell 1995; Braga-Neto et al. 2008).

Most tropical lowland forests differ widely from temperate ones by the presence of a high tree species diversity (Duque 2004), which results in a different supply of substrates and a more diverse substrate diversification in humid tropical lowland forests, which, in turn, may result in a different biodiversity and productivity of macrofungi (Lodge 1997). We compared our results $\left(5,428 \mathrm{~m}^{2}\right)$ with those from a biodiversity and productivity analysis made for a Swiss forest that covered 551 visits in 21 years of examination (Straatsma et al. 2001; 1,500 $\mathrm{m}^{2}$ ). In the Swiss study 71,222 sporocarps were observed representing 408 species. In our study 17,320 individuals were observed representing 404 species. Contrary to the accumulation graph of the Swiss plots that seems to level off (Fig. 5), those from the Colombian forests are still increasing and eventually may turn out to be more species rich. Our knowledge of the actual number of macrofungal species occurring in the Amazon forests is still far from complete, which hampers final conclusions with respect to the quantitative ecological role of fungi in processes such as forest 
regeneration, and as a response to environmental changes. Such precautions make it also impossible at this stage to make any supported statement whether these tropical lowland forests are hotspots for fungal diversity. To answer those questions, follow up studies that asses the fungal diversity during long term monitoring of permanent plots are needed to fully appreciate the functional diversity of mycota in these habitats, and to assess their temporal and spatial dynamics, including the effects of environmental perturbations, including de- and reforestation and climate change (Kauserud et al. 2008). Many new fungal species wait to be described. This is not only true for macrofungi, but also for species of genera such as Penicillium (Houbraken et al. 2011) and Trichoderma (LopezQuintero et al. unpubl. observ.) and most likely many more.

Summarizing, the accumulation curves of species in this study are still increasing, thus indicating that the forests studied support an even higher biodiversity of macrofungi. The number of shared species within the forests occurring in Araracuara and Amacayacu was found to be significantly larger than those between the regions, thus suggesting spatial differentiation of the macromycobiota. In Amacayacu, mushroom communities differed between forests on terra firme and regularly flooded forests (i.e. várzea). A putative ectomycorrhizal forest type dominated by Pseudomonotes tropenbosii yielded some candidate ectomycorrhizal species. A recently cleared patch of forest gave a high number of dead wood-inhabiting fungi. The forests patches studied differed in macrofungal and plant species composition, suggesting complex spatial-temporal relationships between fungal biodiversity and vegetation, plant diversity and soils. The question remains whether it is possible to get a reliable total estimate of macrofungal diversity in such tropical habitats as even after 20 years of intense sampling in a European forest macrofungal species new to the plots still appeared (Straatsma et al. 2001; Egli et al. 2006). An increased future sampling effort is needed to further confirm the differences observed in the species distributions in the different forest plots.

Acknowledgments The authors are greatly grateful to NWO-WOTRO for the financial support of the project (WOTRO grants 895.100.014 and WB 84-525). Logistic support was given by Tropenbos Colombia and we thank Dr. Carlos Rodriguez for this. C.L-Q and A.E.F.M. thank the University of Antioquia for giving time to collect in the Amazonas. Further financial support from the Studienstiftung Mykologie and the CBS-KNAW is greatly appreciated. Finally, we want to thank the indigenous people in Araracuara and Araracuara-Peña Roja and the workers in the Parque Natural Nacional Amacayacu for their willingness to allow us to perform the studies described.

Open Access This article is distributed under the terms of the Creative Commons Attribution License which permits any use, distribution, and reproduction in any medium, provided the original author(s) and the source are credited.

\section{References}

Alexander I, Selosse MA (2009) Mycorrhizas in tropical forests: a neglected research imperative. New Phytol 182:14-16

Alexopoulos CJ, Mims CW, Blackwell M (1996) Introductory mycology, 4th edn. Wiley, New York

Braga-Neto R, Luizão RCC, Magnusson WE, Zuquim G, de Castilho CV (2008) Leaf litter fungi in a Central Amazonian forest: the influence of rainfall, soil and topography on the distribution of fruiting bodies. Biodivers Conserv 17:2701-2712

Brown N, Bhagwat S, Watkinson S (2006) Macrofungal diversity in fragmented and disturbed forests of the Western Ghats of India. J Appl Ecol 43:11-17

Colwell RK (2006) EstimateS: Statistical estimation of species richness and shared species from samples. Version 8.0 
Condit R, Pitman N, Leigh E et al (2002) Beta-diversity in tropical forest trees. Science 295:666-669

Crous PW, Rong IH, Wood A et al (2006) How many species of fungi are there at the tip of Africa? Stud Mycol 55:13-33

Crozier J, Thomas SE, Aime MC, Evans HC, Holmes KA (2006) Molecular characterization of fungal endophytic morphospecies isolated from stems and pods of Theobroma cacao. Plant Pathol 55:783-791

Davies RG, Orme CDL, Storch D et al (2007) Topography, energy and the global distribution of bird species richness. Proc R Soc B 274:1189-1197

De Souza HQ, Aguiar IJA (2004) Diversidade de Agaricales (Basidiomycota) na Reserva Biológica Walter Egler, Amazonas, Brasil. Acta Amazon 34:43-51

Duivenvoorden JF (1996) Patterns of tree species richness in the rain forest of the middle Caquetá area, Colombia, NW Amazonia. Biotropica 28:142-158

Duivenvoorden JF, Lips JM (1993) Ecología del paisaje del Medio Caquetá Memoria Explicativa de los Mapas (landscape ecology of the middle caquetá basin; explanatory notes to the maps). Tropenbos International, Wageningen

Duivenvoorden JF, Lips JM (1995) A land ecological study of soils, vegetation, and plant diversity in Colombian Amazonia. Tropenbos International, Wageningen

Duque AJ (2004) Plant diversity scaled by growth forms along spatial and environmental gradients. A study in the rain forest of NW Amazonia. Dissertation, University of Amsterdam, Amsterdam

Egli S, Peter M, Buser C, Stahel W, Ayer F (2006) Mushroom picking does not impair future harvests:results of a long-term study in Switzerland. Biol. Cons. 129:271-276

Franco-Molano AE, Vasco-Palacios A, López-Quintero CA, Boekhout T (2005) Macrohongos de la región del Medio Caquetá. Multimpresos, Medellín

Gentry AH (1988a) Tree species richness of upper Amazonian forest. Proc Natl Acad Sci USA 85:156-159

Gentry AH (1988b) Changes in plant community diversity and floristic composition on environmental and geographical gradients. Ann Mo Bot Gard 75:1-34

Gibbs HK, Ruesch AS, Achard MK et al (2010) Tropical forest were the primary sources of new agricultural land in the $1980 \mathrm{~s}$ and $1990 \mathrm{~s}$. Proc Nat Acad Sci USA 107:16732-16737

Gómez-Hernández M, Williams-Linera G (2011) Diversity of macromycetes determined by tree species, vegetation structure, and microenvironment in tropical cloud forests in Veracruz, Mexico. Botany 89:203-216

Gotelli NJ, Colwell RK (2001) Quantifying biodiversity: Procedures and pitfalls in the measurement and comparison of species richness. Ecol Lett 4:379-391

Green J, Bohannan JMB (2006) Spatial scaling of microbial biodiversity. Trends Ecol Evol 21:501-507

Hawkins BA, Albuquerque FS, Araujo MB et al (2007) Global evaluation of metabolic theory as an explanation for terrestrial species richness gradients. Ecology 88:1877-1888

Hawksworth DL (1991) The fungal dimension of biodiversity: magnitude, significance, and conservation. Mycol Res 95:641-655

Hawksworth DL (2001) The magnitude of fungal diversity: the 1.5 million species estimate revisited. Mycol Res 105:422-1432

Henkel TW, Meszaros R, Aime MC, Kennedy A (2005) New Clavulina species from the Pakaraima mountains of Guyana. Mycol. Progr. 4:343-350

Holdridge LR (1982) Ecología basada en zonas de vida. Instituto Interamericano de Ciencias Agricoles, San José

Holdridge LR, Grenke WC, Hatheway WH, Liang T, Tosi JA (1971) Forest environmenst in Tropical life Zones: a pilot study. Pergamon Press, Oxford

Hoorn C, Wesselingh FP, Ter Steege H et al (2010) Amazonia through time: Andean uplift, climate change, landscape evolution, and biodiversity. Science 330:927-931

Houbraken J, López Quintero CA, Frisvad JC, Boekhout T, Theelen B, Franco-Molano AE, Samson RA (2011) Five new Penicillium species, $P$. araracuarense, $P$. elleniae, P. penarojense, $P$. vanderhammenii and $P$. wotroi, from Colombian leaf litter. Int J Syst Evol Microbiol 61:1462-1475

Hyde KD (2001) Where are the missing fungi? Does Hong Kong have the answers? Mycol Res 105: 1514-1518

Hyde KD, Bussaban B, Paulus B et al (2007) Diversity of saprobic microfungi. Biodivers Conserv 16:7-35

Jiménez-Valverde A, Hortal J (2003) Las curvas de acumulación de especies y la necesidad de evaluar la calidad de los inventarios biológicos. Revista Iberica de Aracnologia 8:151-161

Kark S (2007) Effects of ecotones on biodiversity. In: Levin S (ed) Encyclopedia of biodiversity. Academic Press, San Diego, pp 1-10

Kauserud H, Stige LC, Vik JO et al (2008) Mushroom fruiting and climate change. Proc Nat Acad Sci USA 105:3811-3814 
Kirk PM, Cannon PF, Minter DW, Stalpers JA (2008) Ainsworth \& Bisby's dictionary of the fungi, 10th edn. Cabi International, Wallingford

Köppen W (1936) Das geographische System der Klimate, vol. 1, part C. In: Köppen W, Geiger R (eds), Handbuch der Klimatologie. Borntraeger, Berlin, Germany

Kreft H, Jetz W (2007) Global patterns and determinants of vascular plant diversity. Proc Nat Acad Sci USA 104:5925-5930

Largent DL (1986) How to identify mushrooms to genus (I) macroscopic features. Mad River Press, Eureka

Lodge DJ (1997) Factors related to diversity of decomposer fungi in tropical forests. Biodivers Conserv 6:681-688

Lodge DJ, Cantrell S (1995) Fungal communities in wet tropical forests: variation in time and space. Can J Bot 73:1391-1398

Lodge DJ, Chapela I, Samuels et al. (1995) A survey of patterns of diversity in non-lichenized fungi. Mitt Eidgenöss Forsch.anst Wald Schnee Landsch 70(1):157-173

Lodge DJ, Ammirati JF, O’Dell TE et al (2004) Terrestrial and lignicolous macrofungi. In: Mueller GM, Bills GF, Foster MS (eds) Biodiversity of fungi. Inventory and monitoring methods. Elsevier, Amsterdam, pp 127-172

Londoño AC (2011) Flora and dynamics of an upland and a floodplain forest in Peña Roja, Colombia Amazon. PhD Thesis University of Amsterdam. Amsterdam, The Netherlands

Londoño AC, Alvarez E (1997) Composición florística de dos bosques (Tierra firme y Varzea) en la región de Aracuara, Amazonia Colombiana. Caldasia 19:431-463

Londoño AC, Alvarez DE, Forero E, Morton CM (1995) A new genus and species of Dipterocarpaceae from the Neotropics I. introduction, taxonomy, ecology and distribution. Brittonia 47:225-236

Mabberley DJ (2008) Mabberley's plant book, 3rd edn. Cambridge University Press, Cambridge

Magurran AE (2004) Measuring biological diversity. Blackwell Publishes, Oxford

Magurran AE, Queiroz H (2010) Evaluating tropical biodiversity: Do we need a more refined approach? Biotropica 42:537-539

Mueller GM, Schmit JP (2007) Fungal biodiversity: what do we know? What can we predict? Biodivers Conserv 16:1-5

Mueller GM, Schmit JP, Leacock PR et al (2007) Global diversity and distribution of macrofungi. Biodivers Conserv 16:37-48

Myers N, Mittermeier RA, Mittermeier CG, da Fonseca GAB, Kent J (2000) Biodiversity hotspots for conservation priorities. Nature 403:853-858

Piepenbring M (2007) Inventoring the fungi of Panamá. Biodivers Conserv 16:73-84

Pimm S, Raven P (2000) Extinction by numbers. Nature 403:843-845

Pinruan U, Rungjindamai N, Choeyklin R et al (2010) Occurrence and diversity of basidiomycetous endophytes from the oil palm, Elaeis guineensis in Thailand. Fungal Divers 41:71-88

Pitman NCA, Terborg J, Silman MR et al (2001) Dominance and distribution of tree species in an upper Amazonian Tierra Firme forest. Ecology 82:2101-2117

Rahbek C, Gotelli NJ, Colwell RK et al (2007) Predicting continental-scale patterns of bird species richness with spatially explicit models. Proc R Soc B 274:165-174

Rudas A, Prieto CA (1998) Análisis florístico del parque Nacional Natural Amacayacu e isla Mocagua. Caldasia 20:142-172

Rungjindamai N, Pinruan U, Choeyklin R, Hattori T, Jones EBG (2008) Molecular characterization of basidiomycetous endophytes isolated from leaves, rachis and petioles of the oil palm, Elaeis guineensis, in Thailand. Fungal Divers 33:139-161

Schmit JP, Lodge DJ (2005) Classical methods and modern analysis for studying fungal diversity. In: Dighton J, White JF, Oudemans P (eds) The fungal community, 3rd edn. Taylor and Francis, Boca Raton, pp 193-214

Schmit JP, Mueller GM (2007) An estimate of the lower limit of global fungal diversity. Biodivers Conserv 16:99-111

Singer R (1965) Monographs of South America basidiomycetes especially those of the east slope of the Andes and Brazil X. Xeromphalina. Bol Soc Argent Bot 10:302-310

Singer R (1976) Marasmieae (basidiomycetes-tricholomataceae). Flora Neotropica Monographs 17:1-347

Singer R (1988) The role of fungi in periodically inundated Amazonian forests. Vegetatio 78:27-30

Singer R, Araujo I (1979) A comparison of litter decomposing and ectomycorrhizal Basidiomycetes in latosol-terra-firme rain forest and white podzol campinarana. Acta Amazon. 9:25-41

Singer R, Araujo I, Ivory MH (1983) The ectotrophically mycorrhizal fungi of the neotropical lowlands, especially central Amazonia. Cramer, Vaduz 
Smith ME, Henkel TW, Aime MC, Fremier AK, Vilgalys R (2011) Ectomycorrhizal fungal diversity and community structure on three co-occurring leguminous canopy tree species in a neotropical rainforest. New Phytol 192:699-712

Smits W (1994) Dipterocarpaceae: mycorrhizae and regeneration. Dissertation, Wageningen University, Wageningen

Straatsma G, Ayer F, Egli S (2001) Species richness, abundance, and phenology of fungal fruiting bodies over 21 years in a Swiss forest plot. Mycol Res 105:515-523

Swapna S, Syed A, Krishnappa M (2008) Diversity of macrofungi in semi-evergreen and moist deciduous forest of Shimoga district-Karnataka, India. J Mycol Plant Pathol 38:21-26

Swift MJ, Heal OW, Anderson JM (1979) Decomposition in terrestrial ecosystems. Blackwell, Oxford

Tedersoo L, Suvi T, Beaver K, Kõljalg U (2007) Ectomycorrhizal fungi of the Seychelles: diversity patterns and hosts sifts from the native Vateriopsis seychallarum (Dipterocarpaceae) and Instia bijuga (Caesalpaniaceae) to the introduced Eucalyptus robusta (Myrtaceae), but not Pinus caribea (Pinaceae). New Phytol 175:321-333

Ter Steege H, Pitman N, Sabatier D et al (2003) A spatial model of tree diversity and tree density for the Amazon. Biodivers Conserv 12:2255-2277

Tobón-M C (1999) Monitoring and modeling hydrological fluxes in support of nutrient cycling studies in Amazonian rain forest ecosystems. Dissertation, University of Amsterdam, Amsterdam

Tuomisto H, Ruokolainen K, Kalliola R et al (1995) Dissecting Amazonian biodiversity. Science 269:63-66

Valencia R, Balslev H, Paz y Miño G (1994) High alpha-diversity in Amazonian Ecuador. Biodivers Conserv 3:21-28

Vasco-Palacios AM, Franco-Molano AE, López-Quintero CA, Boekhout T (2005) Macrofungi (ascomycota, basidiomycota) from the middle Caquetá region, Caquetá and Amazonas departments (Colombia). Biota Colombiana 6:127-140

Vester HFM (1997) The trees and the forest: The role of tree architecture in canopy development; a case study in secondary forest (Araracuara, Colombia). Dissertation, University of Amsterdam, Amsterdam

Vester HFM, Cleef AM (1998) Tree architecture and secondary tropical rain forest development. A case study in Araracuara. Colombian Amazonia. Flora 193:75-97

Whittaker RJ, Nogués-Bravo D, Araújo MB (2007) Geographic gradients of species richness: a test of the water-energy conjecture of Hawkins et al. (2003) using European data for five taxa. Global Ecol Biogeogr 16:76-89

Wright SJ, Mueller-Landau HC (2006) The future of tropical forest species. Biotropica 38:287-301

Zak J (2005) Fungal communities of desert ecosystems: links to climate change. In: Dighton J, White JF, Oudemans P (eds) The fungal community, 3rd edn. Taylor and Francis, Boca Raton, pp 659-682 